\title{
Teaching writing in Arabic to raise students' environmental awareness attitude
}

\author{
Rahmat, Aceng $\bowtie$ \\ Universitas Negeri Jakarta, Indonesia (aceng57@gmail.com)
}

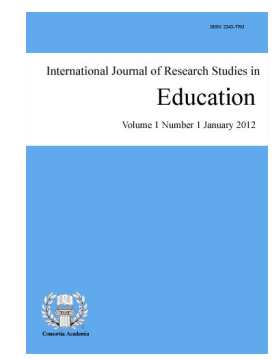

Accepted: 3 January 2015
ISSN: 2243-7703 Online ISSN: 2243-7711

OPEN ACCESS

\section{Abstract}

This model of material development for teaching writing is based on the genre approach. The aim of teaching, in addition to improving the ability of writing, is also to improve the students' awareness attitude toward the environment. Learning Arabic through the genre approach gives the emphasis on the language use in accordance with the functions of language. The model of teaching material development integrates the knowledge of writing, written material and caring attitude. The techniques used in this teaching writing are formulating the hypothesis, collecting the data, analyzing the data, and constructing the findings with the emphasis on caring attitude. The method used in the development of this model of teaching materials was the procedural model proposed by Borg and Gall. Procedural model is a descriptive model that describes the flow or the procedural steps to be followed to produce teaching materials. The stages in the procedural model include: (1) research and gathering initial information, (2) planning, (3) development of initial product format, (4) the initial trial, (5) revision of the product, (6) field trials, (7) revision of the product, (8) field test, (9) the revision of the final product, and (10) the dissemination and implementation. The model was tested in a Madrasah Aliyah in Jakarta. Test results show that t-observed is 12.23 and the t-table at 0.05 significance level is 1.70 . The t-observed is greater than the t-table. This means that there is a significant difference between the learning achievements before and after the use of Arabic language teaching materials integrating the values of environmental concerns. In conclusion, these materials can improve student learning outcomes and effective to use in learning the Arabic language that integrates the attitude values concerning the living environment.

Keywords: model of teaching material development; writing Arabic; the genre approach; attitude; the environmental awareness 


\section{Teaching writing in Arabic to raise students' environmental awareness attitude}

\section{Introduction}

The ecological crisis is "a relationship crisis between human being and culture and the environment where they live and exploit natural resources" which occurs in almost all regions of the world, particularly in parts of Indonesia has invited concern and challenge to the education in Indonesia (Adiwibowo, 2007). The role of education is very important to develop the human resources (HR) that have ecological or environmental insight. School is a strategic vehicle to transform science, technology, culture, ethics, and value. Understanding of the environment, both the dynamics and all aspects of the problem as part of human life, needs to be developed in the school. Environmental based school program is one of the comprehensive environmental education programs that take environmental problems as issues that are integrated in the daily school program. Education is a means to produce human resources capable of maintaining the balance of nature through science.

Environmental education is a hidden curriculum of all subjects in school, that is to increase a sense of caring, and to give students a new perspective, values, knowledge, skills and processes that can lead to changes in behavior and practices that support the conservation of the environment. In accordance with the above mission, the implementation of environmental education programs in schools have to provide atmosphere to the students, so that when they are in school the students are always in contact with environmental education. Arabic is one of the foreign languages has an important role in education. This is because the ability to communicate in both oral and written Arabic is needed to understand and express information, thoughts, feelings, and develop science, technology, and culture. Learning Arabic as intra-school activities can integrate environmental based education into the curriculum being used and at the same time can also be used as a character building of students to have noble characters, good moral, good ethic, kind culture, and civilized manner, especially their love of nature and the surrounding environment.

Arabic is one of the world's languages that hold certain vital roles. Today the economic activity in the Middle East region has become the world appeal. People coming to this region realize that the Arabic, other than English, is the main means of communication and diplomacy and at the same time as a way to approach the society and the Middle Eastern countries. Not only does the entry of foreign investment into the Middle East require Arabic but the urgency of a language can be seen from the function that has an important role in human life. According to Halliday (1976, p. 43) there are three functions of language, namely ideational, interpersonal, and textual. From these functions, human life cannot be separated from language.

Writing is an activity of delivering a message using written language as the medium of communication (Suparno \& Jonah, 2003). Message is the contents or ideas contained in a text, while writing is a symbol or emblem that can be seen and agreed by its users. In a written communication, there are at least four elements that were involved, namely the author as a messenger, the content, media or channel, and the reader as the recipient of the message. So far, learning to write gets more emphasis on the results in the form of writing, not on what should be done when the students write. Students directly practice writing without learning how to write. One of the efforts to improve the quality of teaching writing is to make learning model innovation through the application process genre approach. This approach is a combination of process approach and the genre approach (Lee, Goh, Chan, \& Yang, 2007). To make learning model innovation through the implementation of process genre approach, the appropriate learning tools should be developed. These learning devices include a syllabus, lesson plan, teaching materials, evaluation instruments, and learning guide. The learning tools need to be developed based on the consideration that (1) the teacher does require innovative learning tools, and (2) a learning device serves as a guide for teachers in implementing learning activities. Based on these considerations, this research aims to produce a model of learning aids based on a process genre approach for Islamic High School students (Madrasah Aliyah). 
Teaching writing in Arabic to raise students' environmental awareness attitude

In particular, the purpose of this research is to produce learning materials for writing in Arabic based on the process genre approach. According to Badger and White (2000), there are some important things to consider when learning writing. They are knowledge of the language (as emphasized in the teaching of writing with the product and genre approaches), knowledge about the context in which writing is used in particular of the purpose (as in the genre approach), and the use of language skills (as in the process approach), as well as the development of events through the empowerment potential of students' writing (as in the process approach), and through the provision of inputs as a source of student responses (as in the product approach and the genre approach). The approach in learning writing that takes into account the above considerations is referred to process genre approach (Badger \& White, 2000). Process genre approach includes the creation of conditions when the student is helped to identify the purpose of writing by considering the form, style, and context of a written text that will be drawn. The text with a certain genre is chosen and presented by the teacher who will then encourage the students to analyze the genre. Learning activities with the attention to aspects of language such as the choice of words and grammatical correctness may have to be implemented. Furthermore, with the help of the outline, diagrams, or concept map, students can plan and develop ideas before writing the first draft and revise it in accordance with the objectives and intended real readers. Collaborative aspect is overlooked, as in the process approach that implements student-centered learning.

Learning a language is learning to think, to develop personality, and to develop social skills. Through language human can actualize themselves in accordance with their potential. Realizing the importance of the role of language in everyday life, then learning a language should be able to facilitate these needs. The nature of language is a means of communication and the aim learning the language is to enable students to communicate proficiently, then learning a language should use the communicative approach. It means that planning, implementation, and assessment of learning should be based on the nature of the use of language as a means of communication. The formulation of learning objectives refers to the formation of language competence that can be broadly divided into four language skills. Learning material refers to discourse models which are used as a means to enable students to use language. Methods and learning techniques are learning models that allow students to practice using the language as actual communication in the community.

\section{Learning Materials Based on Environmental Education}

This research is the development of materials for teaching writing in Arabic-based environmental education. Learning a language has a hidden goal that is to learn the language as a communication tool and as a tool for the study of knowledge. In this case, language functions to foster the caring attitude towards the environment. Caring attitude towards the environment is the life skills that can be integrated into learning. In principle, the development of life kills is how one can activate and mobilize all their competencies optimally to be implemented in day-to-day survival. Targeted life skills can be illustrated in the following diagram:

From this diagram, in principle, there are four main components that become the target of the development of life skills, The are the power of thought which includes aspects of managing and thinking skills, feelings associated with the ability to build relationships and develop attention to others, prowess that drives the ability to work and learn or help others, and health that includes skills for survival and recognition of the existence of the self in its environment. These skills can build a person's ability to think critically and creatively, able to develop alternative solutions, consider the pros and cons, and able to make rational decisions in solving all problems. These skills also direct a person to be able to establish interpersonal relationships with others, and able to communicate effectively, able to ensure that the right message is delivered and there is no miscommunication and misinterpretation. Self-awareness, self-esteem and self-confidence are as tools to improve one's understanding of the strengths and weaknesses that exist within him.

This skill will direct a person to be able to seize opportunities that are available and be able to determine the possibilities of treatment. Self-esteem and self-confidence can be a driving force to act or make decisions. The ability to empathize and self-control leads a person to be able to interact with their environment well. 


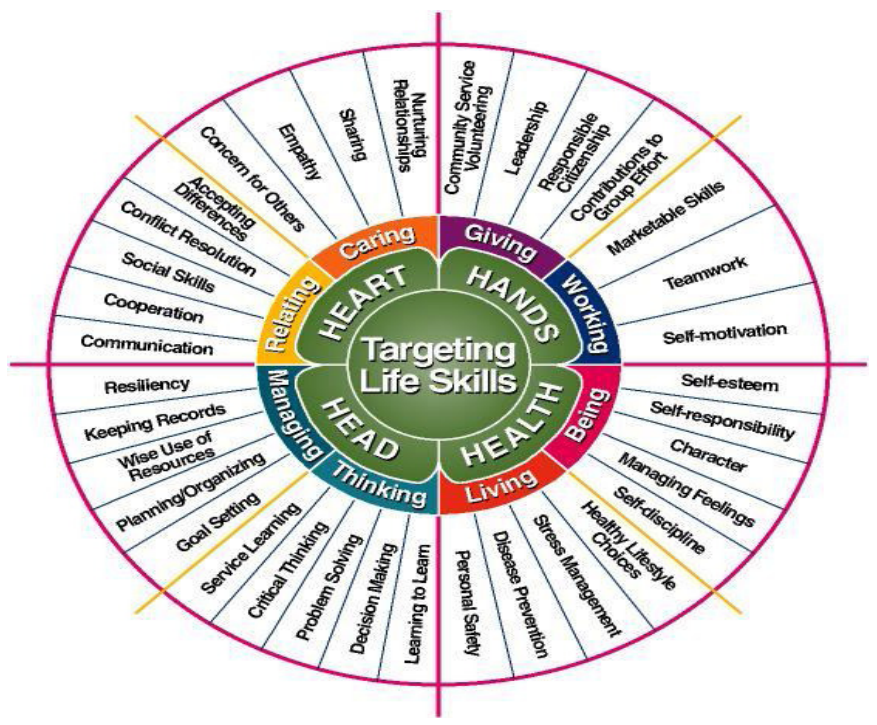

Figure 1. Targeting Life Skills by Rana Tassawar Ali

Source: Retrieved from http://www.comminit.com/global/content/life-skills-children-and-young-people

Environmental Education which is part of the character education which is also implicitly confirmed in the National Long-Term Development Plan (RPJPN) 2005-2015 and is one of the priorities of national development. Murtilaksono et.al (2011) defines environmental education as "Efforts to change behaviors and attitudes of individuals to improve their knowledge, skills, and awareness of environmental values, issues, and problems and to motivate people to participate in efforts to preserve the environment for the present and future generation". In contrast to Bakshi and Naveh (1978, p. 3) defines "Environmental education is, like health, peace or sex education, a field of education that has to do with strong emotions on the side of the learners as well as the teachers". Thus, the teaching materials that are developed are integrative materials that integrate material of concern for the environment in learning to write Arabic in Madrasyah Alyiah.

\section{Research Methods}

This study is the development research that used the procedural model proposed by Borg \& Gall. The procedural model is a descriptive model that describes the flow or the procedural steps to be followed to produce a particular product. The stages of procedural model by Borg and Gall include: (1) research and gathering initial information, (2) planning, (3) development of initial product format, (4) the initial trial, (5) revision of the product, (6) field trials, (7) the revision of the product, (8) field test, (9) the revision of the final product, and (10) the dissemination and implementation.

The above ten steps were not all implemented, but adapted to the needs of the research. The steps of the development carried out in this study were: (1) preparation/pre-development, (2) product development, (3) test phase product, and (4) product revision or improvement.

$>\quad$ First, pre-development stage was done by reviewing the theory, analyzing teaching materials used in the field, interviewing teachers, and distributing questionnaires to students in order to obtain authentic data about the learning needs in the field.

$>$ Second, the stage of product development was the process of realizing a product based on the specifications of the products produced in the pre-development stage.

$>\quad$ Third, the product testing phase was done by the expert judgment, test practitioners, and field tests in 
Teaching writing in Arabic to raise students' environmental awareness attitude

order to determine the validity, the attractiveness and effectiveness of teaching materials.

$>$ Expert judgment was done in State University of Jakarta involving lecturers from Arabic, Indonesian, Biology, and Technology Education departments. Limited field test was done at MAN I Jakarta by involving teachers from Indonesian, Biology and Arabic subjects. Then, the main field test was conducted on a limited group of 56 students of grade X-8 and X-5. At this stage of the field test, researchers used a quasi-experimental research design to determine differences in learning outcomes between the classes that used teaching materials developed by researchers with the classes that used other teaching materials.

$>\quad$ Fourth, revision or refinement stage of the product is a follow up from the various recommendations for improvement of the product. This step resulted on the products that are ready to be implemented and disseminated.

The instruments used in this study can be divided into the pre-development and post-development instruments. Pre-development instrument is any instrument used to gather preliminary information to develop instructional materials. The instrument consists of a matrix of analysis, interview guides, questionnaires, guidelines and literature review. Meanwhile, the post-development instruments are all instruments used to obtain data about the validity of teaching materials and other things to be recognized by researchers from teaching materials that have been developed. The instrument consists of a matrix analysis of teaching materials, teaching materials assessment questionnaire, attractiveness questionnaire, interview guides, observation, and tests. From the above instruments, there are two types of data that could be obtained, numerical data and verbal data. Numerical data include score of instructional materials, score of achievement tests of students in experiment and control classes. Meanwhile, the verbal data include transcript of the interview, results of the analysis of teaching materials, results of the questionnaire and the results of observation.

\section{Results and Discussion}

The learning outcomes that were analyzed were students' learning achievements before and after the experiment. The assessment on students' cognitive achievement was done by using writing test. The following graph describes the results of the tests analysis.

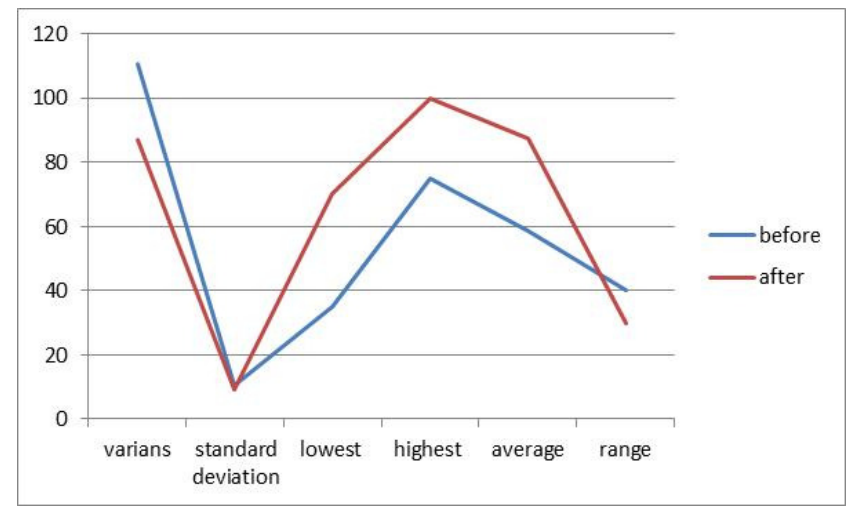

Figure 2. The results of data analysis

Based on the description of the test on writing a report on the result of observation before and after the use of the instructional materials; there some important points that can be revealed. The analysis that was done by using the equation of student learning outcomes data before and after using the new teaching materials shows that the value of the t-observed is 12.23 , and the value of t-table at the significance level of 0.05 is 1.70 . the value of t-observed is greater than the value of $\mathrm{t}$-table. This means that there is a significant difference between the learning outcomes before and after the use of materials for teaching integrated Arabic with the values of environmental concern. Thus, it can be concluded that integrated Arabic material based on the values of 
environmental awareness can improve student learning outcomes and is effectively used in learning Arabic that integrate the values of environmental concern.

The data from affective domain were obtained by using the characteristic behavior observation sheet. Characters of students were observed during the learning process, namely religious character, hard work, curiosity, cooperation (communicative), responsibility, and caring. Average score of students' characters for 4 meetings are plotted in the following graph. The following graph shows that a portrait of the average value of each student's character meetings is always increasing. This means that integrated Arabic language teaching materials with the values of environmental concerns effectively improve the behaviors of students' characters.

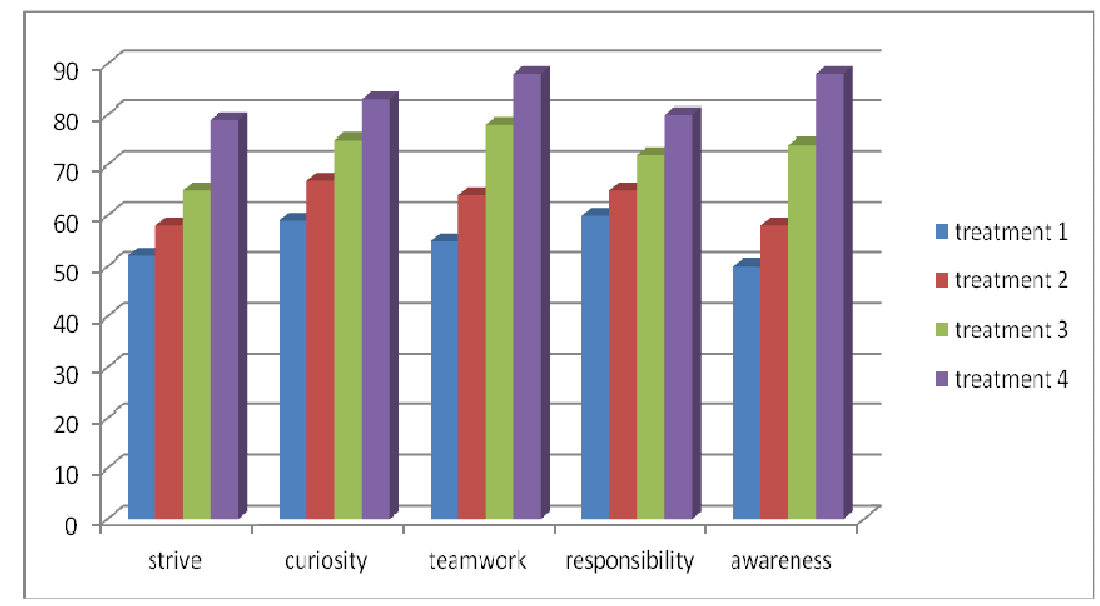

Figure 3. Development of growing a caring attitude towards the environment

To determine the attractiveness of the materials for teaching writing in Arabic based on environmental education, the experimental class was asked to respond the attractiveness questionnaire distributed to them. This questionnaire refers to the opinions stated Reigeluth (2009, p. 77) about the attractiveness criteria, namely the extent to which students enjoy and how much instruction can foster environmental stewardship through Arabic writing lessons.

The results of the questionnaire analysis show that $80.28 \%$ of the respondents say that the attractiveness of the materials is very good, $19.55 \%$ of the respondents says that the attractiveness is good, and $0.17 \%$ says rather good. When results of the analysis are described in detail, the findings show that $79.86 \%$ of the respondents say that the interest of the material is very good and $19.44 \%$ says good. Concerning the opening images, $79.17 \%$ of respondents said that the images are very good and $20.83 \%$ say good. Moreover, in term of the use of color, $70.83 \%$ says very good and $29.17 \%$ says good.

The next aspect is readability of text. The finding shows that $83.33 \%$ of respondents say that the materials are very good, $16.67 \%$ says that they are good and $4.17 \%$ says that the materials are rather good. The next finding shows that $79.17 \%$ of the respondents say that the use of video is very good, and $20.83 \%$ says that the use of video is good. The finding on the interactivity aspect shows that $93.75 \%$ of respondents say that the existing facilities on the attractiveness of teaching materials written in Arabic based educational environment is very good at helping users interact with the materials, and $6.25 \%$ says that the interactivity is good.

The next aspect is the ease of the program. The finding shows that $75.00 \%$ of respondents say the ease of the program is at the level of very good and the remaining $25.00 \%$ says that it is at the good level. In terms of the ease of navigation/move from one menu/ sub menu to another, $66.67 \%$ of the respondents say that the program is very good, and $33.00 \%$ says that the program is good. Moreover, the finding also reveals that $66.67 \%$ of respondents say that the instructions used in the interactive tutorials are very good, $29.17 \%$ say that instructions are good, and $4.17 \%$ say that they are rather good. Finally, in terms of the role of interactive modules, $98.29 \%$ of the respondents say they have very important roles, and the rest $1.71 \%$ say that they are important. 
Teaching writing in Arabic to raise students' environmental awareness attitude

Finally, the finding shows that $67.67 \%$ of the respondents state the materials are very good in terms of the function of pictures to help understanding the material, and $33.33 \%$ say that they good. Furthermore, concerning the statement that interactive modules allow users to learn independently, $91.67 \%$ of respondents say that they are very good and $8.33 \%$ say that they are good. Moreover, concerning the statement that the attractiveness of the materials for teaching writing in Arabic based on environmental education can improve motivation to continue to repeat to get optimal results, $87.50 \%$ of responses are at the very good level and the remaining $12.50 \%$ are at the good level.

\section{Closing Remark}

Model of teaching writing through the genre approach emphasizes the aspects of language function. The function of language as a means of communication is to express an idea or ideas that can be done through writing activities. The model that has been developed is a model that can grow the attitude of concern for the environment that is integrated in learning to write in Arabic. The integrated approach is very suitable for formal education from elementary school to high school because the integrated approach does not require extra time in school so that the implementation of environmental education can be run more efficiently because the students do not need extra time. Nonetheless integrated approach leads teachers to improve their knowledge of environmental materials that will be taught. The environmental based materials are usually integrated in the school curriculum in the form of local content formats. Environment-based education can be developed for teaching writing in Arabic the topic of writing observation report.

The materials for teaching writing an observation report are integrated in the genre approach at the Islamic High School in order to develop the life skills such as caring for the living environment and the activeness of the learners with various aspects of language skills. Indicators of learning to write observation report containing students' awareness on the environment can be measured /assessed. Indicators are developed in accordance with the characteristics of the educational unit (in this study the students of grade X), students' potentials, and formulated in a measurable operational verb such as define, discuss, express, identify, conclude. Through learning to write the students' awareness and sensitivity on the living environment and its problem can be raised, through counseling to individuals or the public about the value of the corresponding system, the strong sensitivity of the concern about the environment and the motivation to actively participate in the preservation of environmental functions and the prevention of environmental damage.

\section{References}

Adiwibowo, S. (2007). Environmental ethics [Etika Lingkungan]. Module class on human ecology, Department of communication and community development. [Modul Kuliah Ekologi Manusia.Departemen Komunikasi dan Pengembangan Masyarakat, Fakultas Ekologi Manusia], IPB, Bogor.

Badger, R., \& White, G. (2000). A process genre approach to teaching writing. English Language Teaching Journal, 54(2), 153-160. http://dx.doi.org/10.1093/elt/54.2.153

Bakshi, T. S., \& Naveh, Z. (1978). Environmental education principal method and application. New York and London: Plenum Press.

Celce-Murcia, M., Dornyei, Z., \& Thurrell, S. (1995). Communicative competence: A pedagogically motivated model with content specifications. Issues in Applied Linguistics, 6, 5-35.

Dick, W., \& Carey, L. (2005). The systematic design of instruction. Boston: Pearson.

Gall, M. D., Gall, J. P., \& Borg, W. R. (2003). Educational research: An introduction (7 ${ }^{\text {th }}$ ed.). Boston: Allyn-Bacon.

Lee, K. C., Goh, H., Chan, J., \& Yang, Y. (2007). Effective college writing: A process genre Approach. Singapore: Mcgraw-Hill.

Murtilaksono, K., Suryana, A., Umar, I., Triasmono, \& Santa. (2011). Secondary and higher education for development of in Indonesia. Journal of Development in Sustainable Agricultural, 6, 35-44.

Muslich, M. (2010). Text book writing. Jogjakarta: Ar-Ruzz Media Group. 
Rahmat, A.

Reigeluth, C. M., \& Chellman, A. C. (2009). Instructional design theories and models (Vol. III). Building a common knowledge base. New York: Taylor \& Francis. 